\title{
The impact of membership on network performance of efficient, innovative and flexible manufacturing enterprises
}

\author{
Xueyuan Wang ${ }^{1}$, Shan $\mathrm{Li}^{1, *}$, and Jiasai Huang ${ }^{1}$ \\ ${ }^{1}$ Harbin University of Science and technology, School of economics and Management, 150080, \\ Harbin, Heilongjiang Province
}

Keywords: Manufacturing enterprise, Network type, Member relationship, Performance.

\begin{abstract}
Making full use of network member resources to improve performance has become a strategic choice for manufacturing enterprises. Based on the analysis of member relationship dimensions and manufacture enterprise network types, the influences among member relationship dimensions and their influences on network performance are discussed. The weighting indexes and standards are designed, and structural equation method is used to test the hypothesis. The following results can be obtained: member relationship dimension self-accelerating effects commonly exit, and "the communication's influence on trust" has become the key for member relation optimization. Trust is important for all networks cooperation. The contract, trust and communication individually become the management key or efficiency, innovation and flexibility manufacturing network.
\end{abstract}

\section{Introduction}

Global economic integration turns the single manufacturing enterprise competition into manufacturing enterprises network competition. Manufacturing enterprise network refers to the multi-enterprise horizontal and vertical connection organizations formed around the value-added activities of enterprises.

Different types of manufacturing enterprises have different ways to improve their network performance: Firstly, some networks achieve value-added through efficient transmission and utilization of resources among members. Lenovo firstly obtained a wide range of network members through mergers and acquisitions (M\&A), it integrated the brands, marketing channels, and other resources of the merged and acquired enterprises to create added value. Lenovo promoted its resources allocation \& controlling capability, and improved its producing efficiency \& competitive advantage, by optimizing continuous connections among its manufacturing network members. Secondly, some manufacturing enterprises gain competitive advantages by providing leading and differentiated products or

* Corresponding author: 1952732981@qq.com 
services through combining innovative capabilities of different members. Huawei firstly built its own enterprise network by jointly establishing R\&D centers and forming technology alliance with some first-class enterprises and universities, and then it continuously improved its innovation ability by integrating technology resources from its network members. Through the paths of "participating into international standards influencing international standards - dominating international standards " based on patents embedding, cross-licensing and patent pools forming, Huawei gains the leadership in product and service, and accordingly enhances the whole performance of manufacturing enterprise network. Thirdly, some manufacturing enterprise networks realize value creation through members' timely insight into external information to quickly meet the need of customers. In the second quarter of 2018, Xiaomi became one of the leading five smart phone manufacturers in the World (the rest were Samsung, Huawei, Apple, and Oppo). Xiaomi formed \& expanded the supply chain and enriched the network members through the "sell - buy" mode. It created added-value through the flexible combination of core and auxiliary network members. It uses Internet technology to break the barriers between supply and demand, and turns hunger marketing into on-demand production, continuously adjusts the quantity and function of products according to customers' requirement, in order to improve network performance through flexible matching.

The synergistic effect of $1+1>2$ is the key to realize the development of manufacturing enterprise networks. Manufacturing enterprises have a large number of network members, its relationships are complex and dynamic, which has become an important factor to affect the network performance of manufacturing enterprises. Different types of manufacturing enterprises have different ways to improve their network performance and the emphasis of member relationship management is also different. Therefore, on the basis of analyzing the dimension of membership, the network member relationship impact on different manufacturing enterprises performance is determined based on contingency theory.

The synergistic effect of $1+1>2$ is the key to realize the development of manufacturing enterprise networks. Manufacturing enterprises have a large number of network members, its relationships are complex and dynamic, which has become an important factor to affect the network performance of manufacturing enterprises. Different types of manufacturing enterprises have different ways to improve their network performance and the emphasis of member relationship management is also different. Therefore, on the basis of analyzing the dimension of membership, the network member relationship impact on different manufacturing enterprises performance is determined based on contingency theory.

\section{Dimensions of membership in manufacturing network}

Different scholars put forward different views on the dimensions of network membership in manufacturing enterprises: Guo and Tang (2017) believe that the member relationship is the contractual relations of responsibility \& power $\&$ interest within a certain period, and the contract is the premise and guarantee to reach the cooperation among members, and a Game Model of membership for the joint contracting was designed. He et al. (2016) believe that the quality of the relationship can be reflected through trust and contractual commitments. Rong and Ma (2015) argue that reliable contracts and trust are equally important to membership, and neither party can be ignored. Therefore, the balance between contract and trust should be balanced to ensure the sustained and healthy development of network membership. (Minnaar et al., 2016). Cheng (2017) propose that the relationship between network members should be reflected through the frequency and depth of communication, and the degree of relationship trust. Sheremeta et al. (2014) believe that the 
communication of members affects the trust of network members and further affects the network membership. On the whole, contract, communication and trust become three important dimensions that reflect the network member cooperation condition, their relationships are as follows:

(1) The division of responsibility \& power \& interest (RPI) among members. In the initial stage of network cooperation, mutual trust among enterprises is relatively fragile, in order to safeguard their cooperative relations, network should clearly divide the RPI among members in the contract. Membership is a transactional relationship, but it is unlike general transaction relationship, in the contract members must share benefits and risks. The restriction and incentive items of sharing RPI among all parties in the contract can help the enterprise network to form a good member relationship of cooperation. Therefore, the division of RPI sharing in contract has become an important dimension to affect member relationship.

(2) The communication of network members. Communication can enhance the understanding of each member on knowledge presentation, resource transmission and reception in the manufacturing, which can reduce the boundary barrier of resource flow. Increasing the frequency of communication will generate more trust, more trust will consolidate more communication, and in this way the network can deepen the relationship among members, and then promote the optimization of network membership and enhance the cohesion of network. It can be seen that manufacturing enterprises network members' commutation can increase members' trust, good communication helps to form a closer, trusted and tacit network membership, therefore communication condition can reflect membership.

(3) The trust among network members. Clear division of RPI is conducive to standardizing members' behavioral relationship. Zhang et al. (2016) propose that enhancing the degree of trust among members can promote the communication and the sharing of tacit knowledge, which stimulates mutual learning and promotes network innovation [4]. A good trust relationship can increase the willingness to cooperate, which is conducive to investing more resources and energy in the subsequent cooperation, so as to gain more value and benefits. In the face of cooperation contradictions, members can actively solve problems to avoid relationship disturbances. It can be seen that increasing members' trust will help to form a win-win, cyclical and sustainable network relationship.

In summary, the dimensions of membership can be obtained in Figure 1.

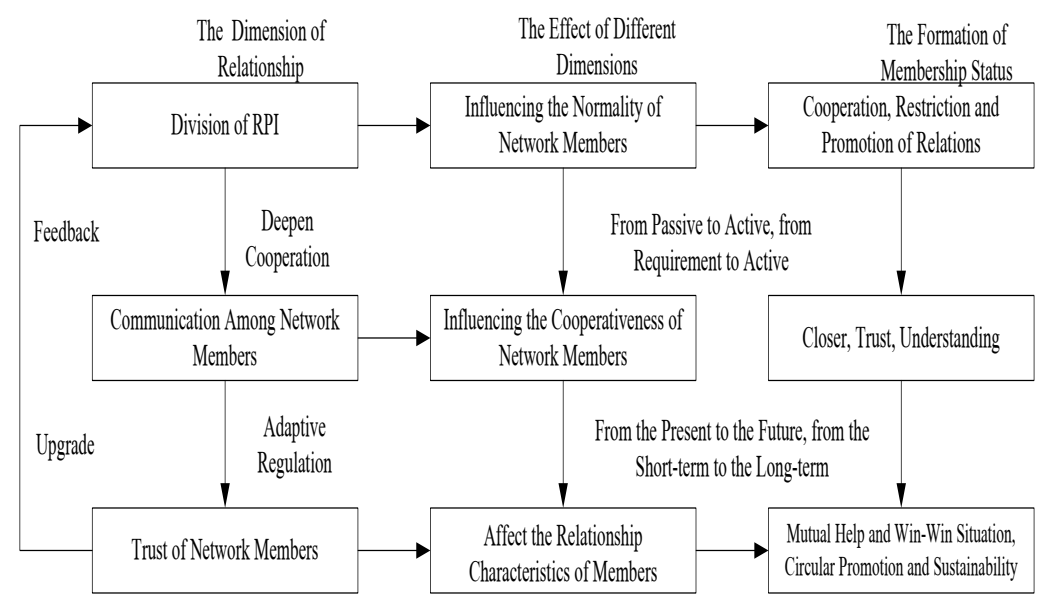

Fig. 1. The membership dimension and the relationship among different dimensions. 


\section{Manufacturing enterprises network type and their performance}

(1) Improving performance through increasing efficiency -- efficient network. Some manufacturing enterprise networks ensure network revenue through effective utilization of resources. Capital is an effective medium for the transformation of various resources in manufacturing enterprises, its utilization efficiency reflects the effectiveness of docking, matching, circulation and application of the whole network resources, such as manpower, technology and knowledge, thus capital utilization efficiency can effectively reflect efficient network performance. This kind of network pays great attention to the cost controlling, including production cost and the transferring cost of member resources (Hu et al., 2015). Through the strict cost control in raw material procurement, warehousing, logistics and transportation, the manufacturing enterprise network can meet the requirements of resource arrangement and fund budget effectively (Kim, 2014). In addition, the efficient network needs to form competitive advantages through effective task decomposition and combination. The decomposition process needs to reflect the serial and parallel relation among tasks, and the modular separation should be based on task characteristics and members, to guarantee scientific task matching. The combination of process needs to ensure that the sub-tasks can be connected organically and the resource combination is synergetic and can be magnified. Capital utilization efficiency ensures the supply of resources for tasks and the recovery of funds, through the control of capitals and the tasks, network can achieve great development, so as to form an efficient network competitive advantage In general, this kind network is adopted in the manufacturing fields with high technology or complex technology, such as large passenger aircrafts, large engines and other advanced differentiated operation networks.

(2) Improving performance through innovation reform --innovative network. The network of innovative manufacturing enterprises focuses on the formation of differential competitive advantage by improving technological novelty or forming innovative management mode. This kind of network attaches great importance to the investment of $\mathrm{R} \& \mathrm{D}$; it improves the creating ability by producing distinctive and novel products or services that can be effectively differentiated from competitors (Gay, 2014). The network is committed to the development of sophisticated technology in the field. By encouraging members to innovate in service concept and product, the network can lead technology innovation in the industry (Kolleck and Bormann, 2014). Through the innovation of business model and management method, a new innovative management mode will be formed in the network, and by constantly exploring the way of production, operation and service, the completive advantage of network will be enhanced. In general, this kind network is adopted in the manufacturing fields with high technology or complex technology, such as large passenger aircrafts, large engines and other advanced differentiated operation networks.

(3) Improving performance through flexible combination - flexible network. The network of some manufacturing enterprises can develop corresponding products or services in a timely manner according to the changes of external environment and markets, so that they can get ahead of their competitors to enter the new markets. When the number of competitors in the market increases, the network can timely realize the leading business transformation or new product upgrading. This kind network mainly improves its competitive advantage in three aspects: demand reflection speed, organizational flexibility and the entry speed of new markets. Firstly, manufacturing enterprise network needs to be able to detect and discern the demand changes of markets ahead of its competitors, and it should form a response scheme rapidly according to the changes (Gong and Janssen, 2012). This fast-acting ability can strive for more time for the follow-up activities of the network. Secondly, the network is required to adjust the R\&D teams, production lines, materials, 
equipment resources and marketing resources according to the action plan, it should change the organizational interface and responsibilities to meet the changing requirements of network tasks (Mirandola et al.,2014). Finally, after completing the internal adjustment, the network should quickly enter the market through marketing channels, thus forming effective market development ability (Schütz and Tomasgard, 2011). In general, this kind network is adopted in manufacturing industries where the life cycle of product or service is short, such as electronic equipment, small household appliances and other manufacturing enterprise networks. It often establishes close relationship with customers to excavate customers' demand so as to improve and adjust the function of products, service, which finally can improve the performance of the whole network.

\section{Theoretical assumptions on the impact of membership on the network performance of manufacturing enterprises}

(1) The clear division of RPI in contract can promote the communication of members. Fair perception of contract among network members will promote the communication of tacit and core knowledge among all members. The perception of fairness in contract procedure will make all parties abide the restriction and regulation of the network, and it will form a benign communication mechanism and repair contradictive relations in time after crisis. Li and Wang (2016) find through the research that the contract can promote the communication of members and provide a formal guarantee for the sharing of members' knowledge. Therefore, hypothesis A is proposed: The division of RPI in contract has significant positive effects on the communication among members.

(2) Communication improves the trust of members. Mackeracher et al. (2018) point out that the higher frequency of the members' communication is, the higher trust level of members is. Network members actively establish resilient boundaries for deep communication, which can promote free collaboration among member and improve members' consciousness of responsibility and mission. Based on the attitude of taking more responsibility of the whole network, the members' dependence and trust degree would be enhanced. The higher communication frequency of network member is and the higher compatibility of manufacturing enterprise network culture is. Communication can reduce opportunistic tendencies and possibility by enhancing the trust among members on the basis of original agreement contracts. Zheng and $\mathrm{Xu}$ (2017) clearly propose that communication contributes to the formation and maintenance of the trust among network members. Positive and repetitive communication is a key step to increase members' attractiveness and reduce conflict, which will help enhance the trust and cohesion of members. Therefore, hypothesis $\mathrm{B}$ is proposed: communication has significant positive effects on the trust of member.

(3) Member trust promotes the division of RPI sharing in contract. The trust of contract computing can ensure that all members agree on the fairness of the contract, so as to realize the optimizing contract governance. The trust of member also can guarantee the effective implementation and flexible adjustment of the RPI constraints in contracts. Trust is conducive to reducing the probability of contract execution disputes among network members, and enhancing the self-restraints of opportunistic behaviors(Alajeely et al., 2015), and trust can reduce members' concern about tacit knowledge sharing leakage, which ensure effective and positive implementation of contractual agreements and enhance the tolerance of contract changes. Therefore, hypothesis $\mathrm{C}$ is proposed: Trust has significant positive effects on the division of members' RPI.

(4) The division of RPI in contract can avoid the problem of time lagging in task convergence and material allocation; and it also contributes to the saving of operation cost and the promoting of capital utilization efficiency. The clear requirement of RPI sharing can expand and enlarge the task changes scope that network members could be treated, thus 
the flexibility of task allocation is increased and the efficiency of tasks implementation is guaranteed. Effective communication helps members to form a consensus concept on resource transfer standards and requirements, which ensures the completing efficiency of tasks and reduces the capital expenditure in negotiation and transaction, and improves the capital utilization efficiency. Finally, trust can reduce the conflicts in benefits distribution, task redistribution and adjustment. Through the synergy effect of $1+1>2$, the quality of tasks will be improved and the subsequent investment is facilitated. When members with high trust cooperate together, their task completion efficiency is always higher than that of others because of high network cohesion. Therefore, hypotheses D1, D2, D3 are proposed: membership relations - the division of RPI, communication, and trust have significant positive effects on the efficient network performance of manufacturing enterprises.

(5) The RPI sharing in contract encourage network members to invest more advanced technology resources through fair technology investment and distribution items. Contract facilitates the acquisition of explicit knowledge; members' communication can promote tacit knowledge acquisition and contracts have a positive moderating effect on tacit knowledge acquisition based on pervious research achievements. Effective communication is conducive to reducing the cost of heterogeneous knowledge transfer, so that the manufacturing enterprise network can effectively integrate the ideas and viewpoints of all members. The manufacturing enterprise network can form novel technologies and enhance technological advancement based on knowledge resources integration. Communication promotes the members' compatibility and their transformation experiences, which are conducive to forming more advanced and effective business models or management methods. High trust reduces members' opportunistic behavior and provides power for value creation, and can motivate members to build learning organizations and input more tacit knowledge, so as to improve technological advancement constantly, and actively respond to the adjustment of management mode, and then carry out follow-up cooperation. Therefore, hypotheses E1, E2, E3 are proposed: membership relations - the division of RPI, communication, and trust have significant positive impact on the innovative network performance of manufacturing enterprises.

(6) The division of member RPI sharing in contract promotes the rapid transfer and flow of various kinds of information among members in accordance with established rules, it also improve the demand reflection speed. Based on the modularization, members' cooperation RPI can be divided clearly, which can improve the convenience, speed and flexibility of cooperation docking. Effective communication is conducive to timely insight, discovery and mining of the markets and the demand changes in different areas of the network, so as to improve the response speed of the network to the environment changes. Good communication and tacit cooperation among network members can ensure the effective transfer of resources, information and knowledge, meanwhile the diffusion rate of network resources would be more rapid, and the organizational flexibility and the ability of manufacturing enterprises network to cope with changes would be significantly improved. High trust encourages members to be optimistic about cooperation and to be more tolerant in resource input and adjustment, so as to make the network much faster and more flexible in response to changes. High trust promotes members' learning and ability development; thus the network members can meet the requirements of more fields and achieve crosscompetence, so as to enhance organizational flexibility and risk management capability. Some relevant research results show that capability trust and benevolence trust have positive effects on the flexibility of engineering price and engineering task adjustment (Shi et al., 2014). Therefore, hypotheses F1, F2, F3 are proposed: membership relations - the division of RPI, communication, and trust have significant positive effects on the flexible network performance of manufacturing enterprises. 


\begin{tabular}{|c|c|c|c|}
\hline \multicolumn{3}{|c|}{ The main item } & $\begin{array}{l}\text { Scoring standards (The network of the } \\
\text { manufacturing enterprise fully meets the following } \\
\text { conditions, then the score is } 9 \text {; if better meets it is } 7 \text {; } \\
\text { if general meets it is } 5 \text {; if not quite meets it is } 3 \text {; if } \\
\text { totally inconsistent it is } 1 \text { point, and } 8,6,4,2 \text { are in } \\
\text { the middle) }\end{array}$ \\
\hline \multicolumn{3}{|c|}{$\begin{array}{l}\text { Network type of manufacturing enterprise } \\
\text { (Choose according to the actual situation of the } \\
\text { enterprise network) }\end{array}$} & $\begin{array}{l}\square \text { The network gains competitive advantages } \\
\text { through resource integration to reduce cost and } \\
\text { improve resource utilization level } \\
\square \text { The network gains competitive advantages } \\
\text { through the research and development of new } \\
\text { products and services } \\
\square \text { The network gains competitive advantages } \\
\text { through the rapid response and adaptation to quickly } \\
\text { enter the market and meet the diversified demands of } \\
\text { customers }\end{array}$ \\
\hline \multirow{4}{*}{$\begin{array}{ll} & \text { Networ } \\
\mathrm{k} & \\
\text { hip } & \end{array}$} & \multicolumn{2}{|c|}{ The division of RPI (DRPI) } & $\begin{array}{l}\text { The network contract mechanism is well enough } \\
\text { to ensure cost and risk sharing, and the benefit is } \\
\text { allocated fairly according to the contribution of } \\
\text { members }\end{array}$ \\
\hline & \multirow{2}{*}{$\begin{array}{l}\text { Communic } \\
\text { ation among } \\
\text { network } \\
\text { members }\end{array}$} & \begin{tabular}{l|l} 
nic & $\begin{array}{l}\text { Frequency } \\
\text { of } \\
\text { communication }\end{array}$ \\
\end{tabular} & $\begin{array}{l}\text { Formal and informal communications are } \\
\text { commonly conducted among network members }\end{array}$ \\
\hline & & $\begin{array}{r}\text { Depth of } \\
\text { communication }\end{array}$ & $\begin{array}{l}\text { Members actively participate in discussions, the } \\
\text { opinions have a positive role, and the network } \\
\text { attaches importance to opinions adoption the } \\
\text { application }\end{array}$ \\
\hline & \multicolumn{2}{|c|}{ The trust of network members } & $\begin{array}{l}\text { Members strive to accomplish their tasks, they } \\
\text { are willing to share tacit knowledge and } \\
\text { communicate with each other. Members are } \\
\text { optimistic about future cooperation }\end{array}$ \\
\hline \multirow{3}{*}{$\begin{array}{l}\text { Networ } \\
\mathrm{k} \\
\text { performance }\end{array}$} & \multirow{2}{*}{$\begin{array}{l}\text { Efficien } \\
\text { t type }\end{array}$} & $\begin{array}{c}\text { Efficiency } \\
\text { capital utilization }\end{array}$ & $\begin{array}{l}\text { Economic indicators perform well, which is } \\
\text { obviously better than similar manufacturing } \\
\text { networks }\end{array}$ \\
\hline & & $\begin{array}{l}\text { Efficiency of the } \\
\text { task completion }\end{array}$ & $\begin{array}{l}\text { Over fulfill task goals, can decompose and } \\
\text { combine tasks scientifically, and task decomposition } \\
\text { matches member capabilities and strengths well }\end{array}$ \\
\hline & \begin{tabular}{|l|} 
Innovat \\
ive type
\end{tabular} & $\begin{array}{l}\text { Technology } \\
\text { novelty degree }\end{array}$ & $\begin{array}{l}\text { Compared with other competitors, their products } \\
\text { or services can be effectively distinguished. }\end{array}$ \\
\hline
\end{tabular}




\begin{tabular}{|c|c|c|}
\hline & $\begin{array}{c}\text { Technology } \\
\text { advanced degree }\end{array}$ & $\begin{array}{l}\text { Products and services are highly innovative; core } \\
\text { technology and assistive technology are in the } \\
\text { leading position in the same field }\end{array}$ \\
\hline & $\begin{array}{c}\text { Model and } \\
\text { method innovation }\end{array}$ & $\begin{array}{l}\text { The manufacturing enterprise network adopts the } \\
\text { new management method, and its operation mode is } \\
\text { advanced }\end{array}$ \\
\hline \multirow{3}{*}{$\begin{array}{l}\text { Flexibl } \\
\text { e type }\end{array}$} & Reflection speed & $\begin{array}{l}\text { Identifying customers' requirement changes in } \\
\text { advance }\end{array}$ \\
\hline & $\begin{array}{l}\text { Organization } \\
\text { Flexibility }\end{array}$ & $\begin{array}{l}\text { The network structure and function can be } \\
\text { adjusted timely according to internal and external } \\
\text { changes and network developing strategies }\end{array}$ \\
\hline & 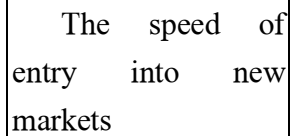 & $\begin{array}{l}\text { Manufacturing networks are always the first to } \\
\text { discover, expand and enter into new markets }\end{array}$ \\
\hline
\end{tabular}

\section{Tests and result analysis of the impact of membership on the network performance of manufacturing enterprises}

(1) Data collection. To scientifically determine the impact of membership on network performance of different manufacturing enterprises, a questionnaire are designed on the basis of related previous literatures (Wang et al., 2017, Xu and Yang, 2017), the main items are shown in Table 1.

Questionnaires are distributed to relevant staffs in the manufacturing or manufacturing service sectors of the network, such as Huawei Technologies Cooperation Limited, Zhongxing Telecommunication Equipment (ZTE), First Automobile Work shop (FAW), Shanghai Automotive Industry Corporation (SAIC), Lenovo Group and Petrochina Cooperation Limited, etc. It covers multiple manufacturing fields, which can effectively reflect the overall situation of manufacturing enterprise network; and it is from managers of middle and senior departments, and also includes junior and first-line managers as well as general technical staffs, which can reflect the opinions of different layers of enterprise networks.

(2) Data calculation. For the items which are reflected by multiple standards, thus simple average weighted summation method is used to determine the unique data corresponding to different items. The amose17.0 software is used for data calculation, the result can be obtained by using structural equation methods, and the results can be seen in figure 2 when the model passes the goodness of fit test and the relationships in the model passes $95 \%$ significance test.

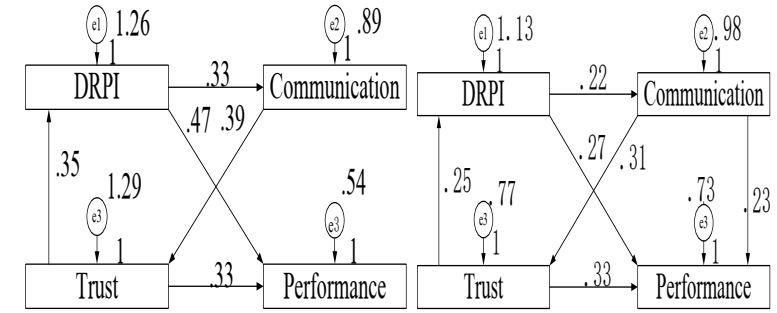

(a) Efficiency Type

(b) Innovative type

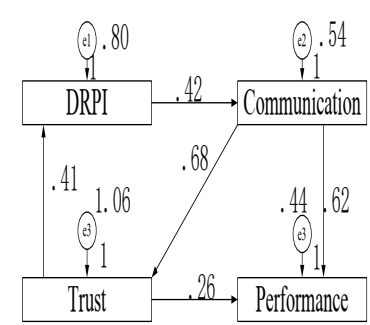

(c) Flexible type

Fig. 2. The role of membership in manufacturing enterprise network performance. 
(3) Results analysis. The results show that the relationship among different dimensions of members and its impact on network performance of different manufacturing enterprises are diverse, the networks of manufacturing enterprise need to carry out diverse member relationship management according to their own types. The details are as follows:

First of all, the promoting effects of three-dimension of membership relationship commonly exist, and the assumptions $\mathrm{A}, \mathrm{B}$ and $\mathrm{C}$ are confirmed in three kinds of networks, which is consistent with the previous research. It can be seen that all types of networks should clarify the RPI sharing in contract and the effective communication can be carried out under the framework of the contract to enhance the degree of trust of members, further enhance the fairness and impartiality of the contract.

Secondly, the assumptions D1, D3, E1, E2, E3, F2, and F3 pass the test. The results show that trust plays a positive role in three networks. Xu and Yang (2017) find that trust plays a positive role in equity-based and contract-based cooperation in promoting cooperation performance. Strengthening member trust is conducive to transferring resources; it is also conducive to sharing and capturing information, which can improve the network performance of different types of manufacturing enterprises [6].

Finally, the assumptions D2, F1 do not pass the test. Member communication has no significant impact on efficient network performance. Studies have shown that frequent and redundant communication among members will affect and delay the action time, which restricts the improvement of network efficiency. In addition, the contract has no significant effect on flexible network performance. When the external environment changes, task may exceed the requirements of contract. In the flexible network, the possibility of breaking through the contract provisions and flexible deployment of tasks is higher than the other two types of networks. More cooperation needs more communication and trust. In order to quickly meet the need of the market, it's useless for enterprise to pay more attention on frequent negotiation and the specific division of RPI in advance. Some scholars believe that it is difficult to specify the task and responsibility requirements of member parties in a dynamic environment; the ambiguity of contract is more suitable to the current economic and the developing market. Therefore, flexible networks should focus on providing effective platforms, channels and media for members' communication. The manufacturing enterprise should focus on information, resource sharing and after-benefit negotiation or distribution to improve the responsiveness to the market of the network.

\section{Conclusions}

In this paper, it reveals that membership includes contract, communication and trust. The network of manufacturing enterprises consists of three types: efficient, innovative and flexible. The performance of different types of network is reflected in different ways, diverse relationship dimensions have different influences on the manufacturing enterprise networks with different types. Based on the analysis of the impact of membership on network performance, through design data collection and calculation test, the following results are obtained: the three dimensions of membership have self-promoting effect, especially in flexible network. Trust has a general impact on the performance of network. Contract, trust and communication respectively have become the focus of the management of efficient. Efficient network should avoid unnecessary communication among members, the flexible networks do not need to overemphasize the division of pre-cooperation contract. The research can provide effective support for the relationship of network members and manufacturing enterprises. In the future, it will further study the determination method of network types and the specific member relationship management methods to provide more operational guidance and reference for manufacturing enterprises. 


\section{References}

1. Guo, S., Tang, B., 'Analysis on the Driving Mechanism of BT Joint Contracting Mode', Journal of Engineering Management, Vol.4, pp.22-26.(2017)

2. He, Y., Ouyang, Y., Liao, N., 'Service Quality, Relationship Quality and Logistics Outsourcing Performance -- a Case Study from the Perspective of Cooperative Relationship', Manage Case Studies and Reviews, Vol.6, PP.567-579.(2016)

3. Cheng, Y., 'The Influence of Collaborative Innovation Network Membership on Collaborative Innovation Performance -- a Case Study of Bio-pharmaceutical Industry', Technical and Economic, Vol.7, pp.22-28.(2017)

4. Zhang, W., Chen, Y., Shi, H., 'Research on Characteristics and Implementation Path of Service Collaboration Network of Inclusive Manufacturing Industry', Scientific and Technological Progress and Countermeasures, Vol.6, pp.53-57. (2016)

5. Li, X., Wang, L., 'The Relationship between Trust and Contract Governance Based on Alliance Knowledge Acquisition', Journal of Management, Vol.6, pp.821-828.(2016)

6. $\mathrm{Xu}, \mathrm{T}$., Yang, J., 'Trust, Cooperative Mode and Cooperative Innovation Performance Among Enterprises -- the Moderating Effect of Knowledge Base Compatibility', East China Economic Management, Vol.12, pp.35- 42.(2017) 